\title{
Oxygen Deficiencies in Titanium Oxide Clusters as Models for Bulk Defects
}

\author{
Lauren F. Heald, ${ }^{1,2}$ Jacob M. Garcia, ${ }^{1,2}$ and Scott G. Sayres ${ }^{1,2, *}$ \\ ${ }^{1}$ School of Molecular Sciences, Arizona State University, Tempe, AZ 85287 \\ ${ }^{2}$ Biodesign Center for Applied Structural Discovery, Arizona State University, Tempe, AZ 85287
}

ABSTRACT: TD-DFT calculations were performed on neutral $\mathrm{Ti}_{\mathrm{n}} \mathrm{O}_{2 \mathrm{n}}, \mathrm{Ti}_{\mathrm{n}} \mathrm{O}_{2 \mathrm{n}-1}$, and $\mathrm{Ti}_{\mathrm{n}} \mathrm{O}_{2 \mathrm{n}-2}$ clusters, where $\mathrm{n} \leq 7$. Our calculations
show that the $\mathrm{Ti}_{\mathrm{n}} \mathrm{O}_{2 \mathrm{n}}$ clusters are closed shell systems containing empty d orbitals and that the partially filled d orbitals of the suboxide
clusters have a profound effect on their structural, electronic, and topological properties. The low energy photoexcitations of $\mathrm{Ti}_{\mathrm{n}} \mathrm{O}_{2 \mathrm{n}}$
clusters are all $\mathrm{O}-2 \mathrm{p}$ to Ti- $3 \mathrm{~d}$ transitions, while the open-shell suboxide clusters are all characterized by d-d transitions that occur at
a much smaller optical gap. Upon photoabsorption, the localization of the hole is accompanied by a local bond elongation, i.e., polaron
formation, whereas d-electrons are generally delocalized among the cluster. Several of the compact of the $\mathrm{Ti}_{\mathrm{n}} \mathrm{O}_{2 \mathrm{n}-2}$ structures contain
higher symmetry which is reflected in their relative stability in the experimental cluster distribution. In particular, the tetrahedral
symmetry of the optimized ground state structure for $\mathrm{Ti}_{4} \mathrm{O}_{6}$ inhibits charge carrier localization and therefore contains higher stability.

\section{Introduction}

Titanium oxides, especially titanium dioxide $\left(\mathrm{TiO}_{2}\right.$ or titania), are versatile materials which are widely used in industrial processes given their relative abundance and low toxicity. ${ }^{1,2}$ Bulk titania has garnered significant attention for its role as an active n-type semiconductor in dye-sensitized solar cells, ${ }^{3}$ as an environmental cleaning agent through photoreduction of organic pollutants, ${ }^{4}$ as a catalyst in water splitting, ${ }^{5}$ and as a prominent white pigment in industrial products. ${ }^{6}$ Titanium oxides are the archetypal strongly correlated material, meaning their electronic properties are strongly connected to the local geometric structure. Photoexcitation produces an electron and hole pair (exciton) which is responsible for redox photocatalytic reactions. The charge carriers are often accompanied by lattice vibrations that are collectively known as polarons. Polaron formation and related self-trapped exciton formation have a strong impact on the photoactivity of titania. ${ }^{7}$ Small polaron formation occurs spontaneously in perfect lattices and is enhanced near defect sites, which can trap mobile carriers at recombination centers, decrease their mobility, and affect the overall activity of the material. ${ }^{7-9}$

The most studied polymorphs of $\mathrm{TiO}_{2}$ processes are anatase and rutile, which both have tetragonal crystal structures and contain $\mathrm{Ti}^{4+}$ coordinated to six $\mathrm{O}^{2+}$ ions. ${ }^{1,2,10}$ In the bulk, the reactivity and catalytic properties are driven by changes in the phase, size, and defect concentration. Despite its wide usage, the photo-application of $\mathrm{TiO}_{2}$ is limited by its large bandgap of $3.0 \mathrm{eV}$ for the rutile structure and $3.2 \mathrm{eV}$ for the anatase structure. ${ }^{6}$ This high bandgap impedes their use to only a fraction of the sun's emission spectrum. In practice, less than $10 \%$ of solar radiation has sufficient energy to participate directly in photocatalysis. Defect engineering has been a prominent research focus for tailoring the electronic, magnetic, optical, mechanical, and quantum properties, and is crucial for activation of heterogeneous photocatalytic processes. ${ }^{2,11}$

In an effort to utilize more of the sun's visible spectrum, increased attention has been invested in the synthesis of titania materials containing large numbers of defect sites, including black $\mathrm{TiO}_{2}$ and the Magnéli phase. ${ }^{711-23}$ The introduction of defects produces structural distortions in the local symmetry of metal centers, thus influencing both charge transport and recombination during the photocatalytic process. ${ }^{2,18,20,24,25}$ Black $\mathrm{TiO}_{2}$ contains point defects which enable it to absorb a large section of the visible spectrum enabling an increased photocatalytic behavior compared to pristine $\mathrm{TiO}_{2}{ }^{2}{ }^{2,17}$ The point defects in black $\mathrm{TiO}_{2}$ have been shown to produce localized states below the conduction band, valance band upshifts, and both conduction band and valance band tails. ${ }^{2}$ Magnéli phase refers to ordered $\mathrm{O}$ deficient $\mathrm{TiO}_{2}$, i.e. $\mathrm{Ti}_{\mathrm{n}} \mathrm{O}_{2 \mathrm{n}-1}$ where $\mathrm{n}=4-9$, with $\mathrm{Ti}_{4} \mathrm{O}_{7}$ being the most reduced. ${ }^{11,16}$ In contrast to disordered defect sites, the Magnéli phase is an ordered form of reduced titania and is characterized by planar defects. ${ }^{26}$ They are desirable as they exhibit a high electrical conductivity that is comparable to carbon. ${ }^{26}$ Both black $\mathrm{TiO}_{2}$ and Magnéli phase materials contain large fractions of $\mathrm{O}$ defect sites (and related $\mathrm{Ti}^{3+}$ sites) which act as the active sites for catalytic activity ${ }^{27}$.

Despite the increased absorption of reduced titania in the visible region, a precise understanding of the structural and electronic nature of these catalytically active sites remains elusive. The number and signature of spin active $\mathrm{Ti}^{3+}$ sites surrounding $\mathrm{O}$ defects are thought to be the dominant contributing factor underneath the different catalytic performance of reduced titania. ${ }^{2,23,28}$ Therefore, a thorough understanding of the effect of $\mathrm{O}$ vacancies on the behavior of excitons, polarons, and free charge carriers (electrons and holes) in titania is needed. The localization and stabilization of $3 \mathrm{~d}$ electron character on reduced Ti remains elusive and is critical for understanding the 
role of defects in transport phenomena. Moreover, it is not clear if the excess electron density fully localizes on a single Ti ion, or if it is delocalized over several sites.

Gas-phase clusters can be employed as models for the point defects in bulk systems to reveal how local changes in geometric structure influences dynamics and charge transport. The atomic precision of clusters provide specific information on what factors enable polaron formation which is known to lower electron transport of $\mathrm{TiO}_{2}$ nanotubes, nanofilms, nanoparticles, and bulk materials. ${ }^{7,23}$ Our recent work on closed shell neutral $\mathrm{Ti}_{\mathrm{n}} \mathrm{O}_{2 \mathrm{n}}$ clusters revealed the electronic properties of the $\mathrm{S}_{1}$ excited state are correlated with the UV-excited state subpicosecond lifetimes. ${ }^{29}$ However, suboxides retain partially filled d-orbitals, which lead to profound changes in their electronic and photoabsorption properties. Here, we extend our previous theoretical approach ${ }^{29}$ to the study of suboxide clusters, as models for $\mathrm{O}$ vacancies, to determine the effect that partially filled d-orbitals have on the electronic and structural properties of titanium oxide.

\section{Methods}

Titanium oxide cluster $\left(\mathrm{Ti}_{\mathrm{n}} \mathrm{O}_{2 \mathrm{n}}, \mathrm{Ti}_{\mathrm{n}} \mathrm{O}_{2 \mathrm{n}-1}\right.$ and $\left.\mathrm{Ti}_{\mathrm{n}} \mathrm{O}_{2 \mathrm{n}-2}\right)$ geometries were optimized at the density functional theory (DFT) level within the Gaussian16 software suite ${ }^{30}$ using the CAMB3LYP ${ }^{31}$ potential and 6-311G++ $(3 \mathrm{~d} 2 \mathrm{f}, 3 \mathrm{p} 2 \mathrm{~d})$ basis set (Figure 1). The excited state properties were calculated within the Tamm-Dancoff approximation ${ }^{32}$ to time dependent-DFT (TDDFT). Previous research on metal clusters has shown the efficacy of using TD-DFT for predicting optical absorption spectra of metal clusters. ${ }^{33}$ Although the accuracy of the electronic properties calculated for the clusters depends strongly on the choice of basis set, the CAM-B3LYP basis set and TD-DFT calculations are effective for excited state determination and charge transfer properties. ${ }^{34,35}$ The lowest 100 excited states were determined using TD-DFT. The difference between the atomic contributions to the occupied and valence orbitals for each excited state are used to quantify the ligand-to-metal charge transfer (LMCT) and metal-to-metal charge transfer (MMCT) character.

Energetic parameters including vertical values for ionization potential $\left(\mathrm{I}_{\mathrm{P}}\right)$, electron affinity $\left(\mathrm{E}_{\mathrm{a}}\right)$, optical gap $\left(\mathrm{O}_{\text {gap }}\right)$, $\mathrm{HOMO} / \mathrm{LUMO}$ gap, and exciton binding energy $\left(\mathrm{E}_{\mathrm{x}}\right)$ were calculated using the optimized energy and structure of the $\mathrm{S}_{0}(\mathrm{Ta}-$ ble 1) and $S_{1}$ states (Table $S 1$ ). The values for $I_{P}$ and $E_{a}$ were determined as the difference between the neutral and cation and anion configurations of the clusters at the ground state geometry. Neutral clusters are all singlets, and the cations and anions are assumed to be in a doublet state. The $\mathrm{O}_{\text {gap }}$ is defined as the minimum photon absorption energy required to produce an excited electron hole pair, or exciton. The exciton binding energy is calculated as

$$
E_{x}=I_{P}-E_{a}-O_{g a p} .
$$

Topological descriptors for the first excited state were calculated for the $\mathrm{S}_{0}$ and $\mathrm{S}_{1}$ geometries and compared against previously reported information for stoichiometric clusters. ${ }^{36} \mathrm{Be}-$ cause photoexcitation involves contributions from many occupied and virtual orbitals, it is convenient to represent the location of the electron and hole as their charge densities. Therefore, we employed topological descriptors, such as $\mathrm{d}_{\mathrm{eh}}$ (distance between centroid of the electron and hole densities), ${ }^{37,38} \sigma$ (degree of delocalization of the RMS density of the electron and the hole), and $\Lambda$ (percent overlap of the electron and hole wavefunctions) as analytical tools. The centroid of the electron and the hole is found following

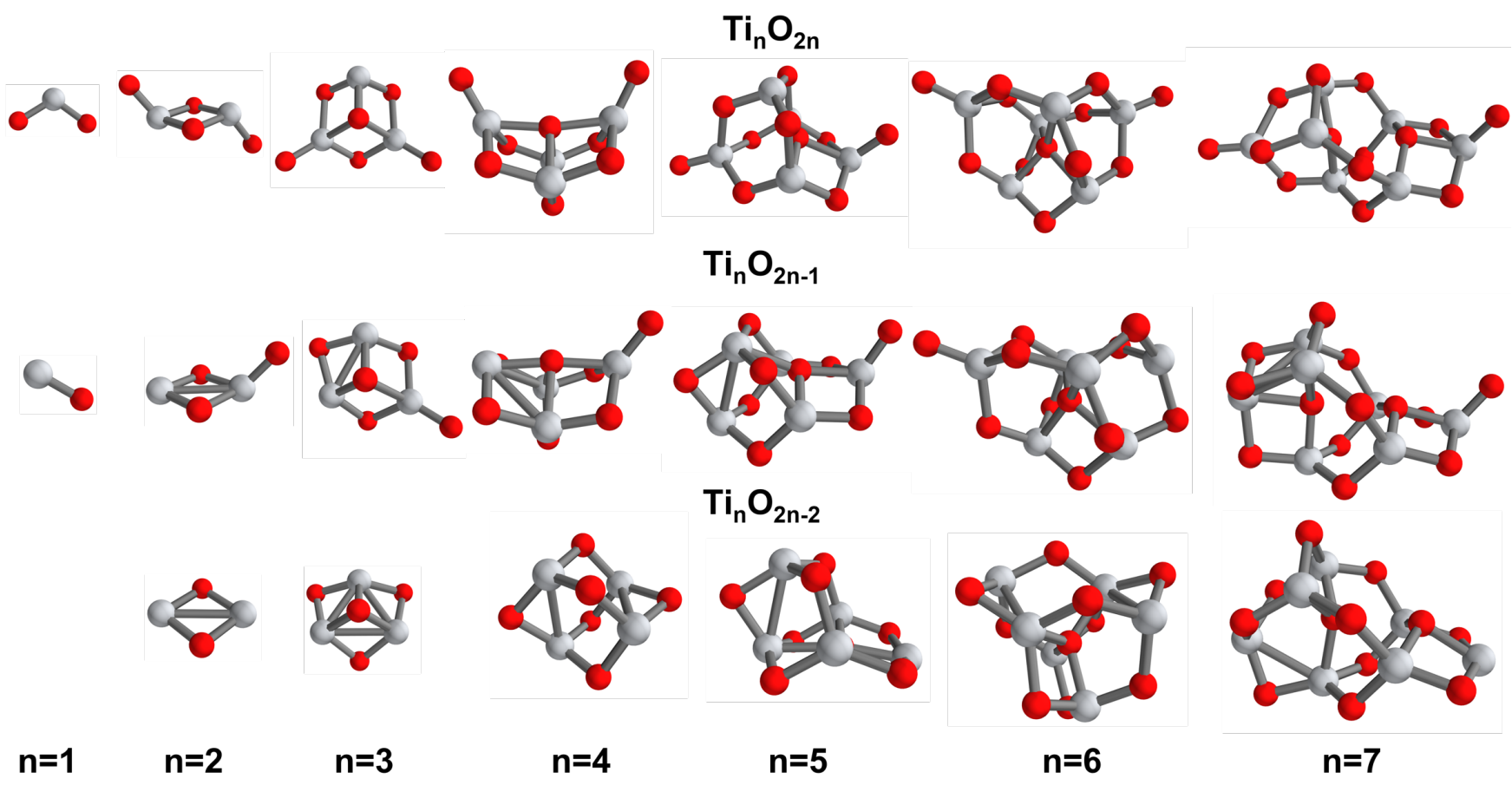

Figure 1. Optimized ground state structures of $\mathrm{Ti}_{n} \mathrm{O}_{2 \mathrm{n}-\mathrm{x}}$ clusters $\mathrm{n}=1-7$ and $\mathrm{x}=0-2$. The gray and red spheres represent the $\mathrm{Ti}$ and $\mathrm{O}$ atoms, respectively. Ti-Ti bonds are drawn if their distance is less than $2.72 \AA$, and bond order is not illustrated. 


$$
X_{e}=\int x \rho_{e}(r) d r
$$

where $\mathrm{X}_{\mathrm{e}}$ is the centroid position for the $\mathrm{x}$ value of the electron, and $\rho_{e}$ is the electron density at point $r$. Similar equations are used for $\mathrm{y}$ and $\mathrm{z}$. The $\mathrm{d}_{\mathrm{eh}}$ is calculated via

$$
d_{e h}=\sqrt{\left(d_{x}\right)^{2}+\left(d_{y}\right)^{2}+\left(d_{z}\right)^{2}}
$$

where $\mathrm{d}_{\mathrm{x}}=\left|\mathrm{X}_{\mathrm{e}}-\mathrm{X}_{\mathrm{h}}\right|$. The $\sigma$ values for the electron and hole are

$$
\sigma=\sqrt{\int(r-R)^{2} \rho(r) d r},
$$

where $\mathrm{R}$ is the distance from the centroid value for the electron or hole. Large $\sigma$ values indicate delocalized orbitals. ${ }^{37}$ The $\Lambda$ parameter, which quantifies the degree of overlap between the wavefunctions is found following

$$
\Lambda=\frac{\sum_{o, v} C_{o v}^{2} o_{o v}}{\sum_{o, v} C_{o v}^{2}}
$$

where $\mathrm{O}_{\text {ov }}$ is the overlap between each occupied-virtual pair and is found following

$$
O_{o v}=\int\left|\varphi_{o} \| \varphi_{v}\right| d r
$$

The spatial wavefunction distributions for the occupied and virtual pairs involved in the excitation are represented by $\varphi_{\mathrm{o}}$ and $\varphi_{\mathrm{v}}$, respectively. $\mathrm{O}_{\mathrm{ov}}$ is weighted by the contribution coefficient for each pair $\left(\mathrm{C}_{\mathrm{ov}}\right)$. The $\Lambda$ parameter ranges between 0 and 1 to describe the percent overlap of the wavefunctions. ${ }^{39}$ Topological parameters for the $\mathrm{S}_{0}$ and $\mathrm{S}_{1}$ states are listed Table $\mathrm{S} 2$. The binding energy per $\mathrm{O}$ atom is calculated to determine the relative stability of the clusters as

$$
E_{b}=-\left(E_{T i_{n} O_{m}}-n E_{T i}-(m / 2) E_{O_{2}}\right) / m \text {. }
$$

\begin{tabular}{|c|c|c|c|c|c|}
\hline & $\mathrm{I}_{\mathrm{P}}$ & $\mathrm{E}_{\mathrm{a}}$ & $E_{x}^{a}$ & $\begin{array}{l}\text { HOMO- } \\
\text { LUMO }\end{array}$ & $\begin{array}{l}\text { Optical } \\
\text { gap }\end{array}$ \\
\hline $\mathrm{TiO}_{2}$ & 10.02 & 1.74 & 5.43 & 6.50 & 2.85 \\
\hline \multirow[t]{2}{*}{$\mathrm{TiO}$} & 5.92 & 2.32 & 2.86 & 4.12 & 0.74 \\
\hline & -- & -- & -- & -- & -- \\
\hline $\mathrm{Ti}_{2} \mathrm{O}_{4}$ & 11.05 & 1.60 & 5.50 & 7.75 & 3.95 \\
\hline $\mathrm{Ti}_{2} \mathrm{O}_{3}$ & 6.33 & 2.07 & 3.93 & 4.17 & 0.33 \\
\hline $\mathrm{Ti}_{2} \mathrm{O}_{2}$ & 5.37 & 0.79 & 4.45 & 4.33 & 0.13 \\
\hline $\mathrm{Ti}_{3} \mathrm{O}_{6}$ & 10.33 & 2.99 & 3.38 & 6.49 & 3.96 \\
\hline $\mathrm{Ti}_{3} \mathrm{O}_{5}$ & 7.87 & 1.24 & 5.28 & 5.19 & 1.36 \\
\hline $\mathrm{Ti}_{3} \mathrm{O}_{4}$ & 6.36 & 0.93 & 4.27 & 4.88 & 1.16 \\
\hline $\mathrm{Ti}_{4} \mathrm{O}_{8}$ & 11.29 & 1.60 & 5.56 & 8.02 & 4.13 \\
\hline $\mathrm{Ti}_{4} \mathrm{O}_{7}$ & 7.15 & 1.82 & 4.75 & 4.80 & 0.58 \\
\hline $\mathrm{Ti}_{4} \mathrm{O}_{6}$ & 6.90 & 1.58 & 4.25 & 4.48 & 1.06 \\
\hline $\mathrm{Ti}_{5} \mathrm{O}_{10}$ & 11.21 & 2.40 & 4.79 & 7.70 & 4.02 \\
\hline $\mathrm{Ti}_{5} \mathrm{O}_{9}$ & 8.05 & 2.26 & 4.17 & 5.39 & 1.62 \\
\hline $\mathrm{Ti}_{5} \mathrm{O}_{8}$ & 6.03 & 1.41 & 4.41 & 4.09 & 0.20 \\
\hline $\mathrm{Ti}_{6} \mathrm{O}_{12}$ & 11.42 & 2.43 & 4.49 & 7.65 & 4.50 \\
\hline $\mathrm{Ti}_{6} \mathrm{O}_{11}$ & 7.53 & 2.53 & 3.88 & 4.65 & 1.12 \\
\hline $\mathrm{Ti}_{6} \mathrm{O}_{10}$ & 6.80 & 1.61 & 4.16 & 4.74 & 1.03 \\
\hline $\mathrm{Ti}_{7} \mathrm{O}_{14}$ & 11.23 & 2.74 & 4.04 & 7.88 & 4.45 \\
\hline $\mathrm{Ti}_{7} \mathrm{O}_{13}$ & 7.17 & 2.31 & 3.98 & 4.60 & 0.88 \\
\hline $\mathrm{Ti}_{7} \mathrm{O}_{12}$ & 6.07 & 2.34 & 3.66 & 4.03 & 0.08 \\
\hline
\end{tabular}

Table 1: Energetic information for the ground states of the stoichiometric, missing one $O$, and missing two $O$ clusters. All units are in $\mathrm{eV}$.

${ }^{\text {a }} E_{x}$ is calculated for the first excited state of the $S_{0}$ configuration

\section{Results and Discussion}

Although sub-nanometer clusters form geometric structures which are far from the crystalline lattice of the bulk, their electronic structure mimics the band structure of bulk materials, except that their atomic orbitals form discrete energy levels instead of continuum bands. Formally, each $\mathrm{O}$ atom removes two electrons from the d-orbitals of the $\mathrm{Ti}$ atoms resulting in closed electronic shells. For example, the $\mathrm{Ti}_{\mathrm{n}} \mathrm{O}_{2 \mathrm{n}}$ clusters contain no $\mathrm{d}$ electrons, making the HOMO composed of O-2p orbitals and the LUMO is composed of Ti-3d orbitals, mimicking the valence and conduction bands of the bulk band structure. Instead of octahedral metal centers, the Ti atoms in sub-nanometer titanium oxide clusters are typically tetra-coordinated, and the $\mathrm{O}$ atoms serve as bridging atoms. Our $\mathrm{Ti}_{\mathrm{n}} \mathrm{O}_{2 \mathrm{n}}$ structures are in agreement with previously determined structures using numerous computational methods. ${ }^{40-46}$ Each stoichiometric cluster, $\mathrm{Ti}_{\mathrm{n}} \mathrm{O}_{2 \mathrm{n}}$, contains two dangling $\mathrm{O}$ atoms. They are closed shell species, where all of the Ti-d electrons are transferred to the $\mathrm{O}$ atoms, and therefore serve as models for the electronic structure of defect-free bulk titania. Similarly, suboxide clusters act as models for the distortions caused by $\mathrm{O}$ vacancies in $\mathrm{TiO}_{2}$ materials. Far less work has been performed on the suboxide clusters. ${ }^{47}$ Our clusters show the suboxide clusters contain a similar cage structure as the stoichiometric series, except are missing either one or both terminal O. However, the formation of defect sites is accompanied by a local distortion as well as an overall compression of the cluster. The optimized ground state structures illustrate the location and geometric compression of atoms shifting away from the $\mathrm{O}$ vacancy. The exception to this trend is $\mathrm{Ti}_{4} \mathrm{O}_{6}$, where substantial rearrangement occurs leading to a more stable tetrahedral geometry. The $\mathrm{C}_{\mathrm{s}}$ symmetry group of odd-numbered $\mathrm{Ti}_{\mathrm{n}} \mathrm{O}_{2 \mathrm{n}}$ clusters ensures that the two terminal $\mathrm{O}$ are not equivalent, and the $\mathrm{O}$ with the weaker bond is absent in the $\mathrm{Ti}_{2} \mathrm{O}_{2 \mathrm{n}-1}$ series. For example, for $\mathrm{Ti}_{5} \mathrm{O}_{9}$, removal of one terminal $\mathrm{O}$ atom results in an isomer that is $1.25 \mathrm{eV}$ higher in energy than removal of the other. In the $\mathrm{Ti}_{\mathrm{n}} \mathrm{O}_{2 \mathrm{n}-2}$ series, both terminal $\mathrm{O}$ atoms are absent resulting in all remaining $\mathrm{O}$ atoms being bridged between two Ti atoms. The variation in local cluster geometries provides a variety of configurations that mimic the active sites of bulk surfaces and can be employed to understand which factors drive polaron formation and related charge carrier localization.

Structure and Stability. Neutral clusters were produced by the ablation of a Ti rod using the second harmonic of a $\mathrm{Nd}$ :YAG laser while synchronized to a pulsed beam of $1 \% \mathrm{O}_{2}$ seeded in He. The neutral cluster distribution was measured using a home-built Wiley-McLaren ${ }^{48}$ type time-of-flight mass spectrometer coupled to a femtosecond laser for ionization. Detailed information on the experimental setup was previously described. ${ }^{49}$ The static mass spectrum was published previously ${ }^{29}$ and reveals the presence of neutral clusters containing several stoichiometries, with the $\mathrm{Ti}_{\mathrm{n}} \mathrm{O}_{2 \mathrm{n}-1}$ series generally being the most prominent. The $\mathrm{Ti}_{\mathrm{n}} \mathrm{O}_{2 \mathrm{n}}$ series are the least intense cluster series in the distribution obtained through femtosecond ionization of neutral clusters produced via laser ablation. This is in agreement with both our $\mathrm{E}_{\mathrm{b}}$ calculation as well as previous results where VUV light was employed for ionization. ${ }^{50}$ The relative signal intensities of the clusters (Figure 2) in the experimental mass spectrum also show several outliers that have increased signal relative to their neighboring peaks and suggest they contain an enhanced stability. Specifically, $\mathrm{Ti}_{2} \mathrm{O}_{2}, \mathrm{Ti}_{4} \mathrm{O}_{6}$, and $\mathrm{Ti}_{6} \mathrm{O}_{10}$ exhibit increased experimental signal relative to the other clusters in the $\mathrm{Ti}_{\mathrm{n}} \mathrm{O}_{2 \mathrm{n}-2}$ series as well as their $\mathrm{Ti}_{\mathrm{n}} \mathrm{O}_{2 \mathrm{n}}$ and $\mathrm{Ti}_{\mathrm{n}} \mathrm{O}_{2 \mathrm{n}-1}$ counterparts. Our calculations reveal that the symmetry 
groups of $\mathrm{Ti}_{2} \mathrm{O}_{2}\left(\mathrm{D}_{2 \mathrm{~h}}\right), \mathrm{Ti}_{4} \mathrm{O}_{6}\left(\mathrm{~T}_{\mathrm{d}}\right)$, and $\mathrm{Ti}_{6} \mathrm{O}_{10}\left(\mathrm{C}_{2}\right)$ are higher than the $\mathrm{C}_{\mathrm{s}}$ of the other $\mathrm{Ti}_{\mathrm{n}} \mathrm{O}_{2 \mathrm{n}-2}$ clusters. This high symmetry accounts for their increased signal intensity in the mass spectrum. All clusters in the $\mathrm{Ti}_{\mathrm{n}} \mathrm{O}_{2 \mathrm{n}-1}$ series, except $\mathrm{Ti}_{6} \mathrm{O}_{11}\left(\mathrm{C}_{1}\right.$ symmetry group), contain a mirror plane on the cluster through the terminal $\mathrm{O}$ and bisecting two $\mathrm{Ti}$ atoms nearest the $\mathrm{O}$ vacancy that are connected by a covalent bond. They also contain only tetra-coordinated $\mathrm{Ti}$ atoms with $\mathrm{Ti}-\mathrm{Ti}$ bonds arising to stabilize the $\mathrm{d}$ electrons.

In bulk, the average Ti-O bond length is $1.95 \AA .{ }^{10}$ The stoichiometric clusters offer similar bond lengths, with an average of $1.9 \AA$ for bridging $\mathrm{O}$ atoms. However, the terminal $\mathrm{O}$ bonds are $1.6 \AA$, suggesting the presence of double bonds. ${ }^{51}$ In $\mathrm{O}$ deficient clusters, the bridging Ti-O bonds are compressed, especially near the reduced Ti atom. Although the average metal-tometal distance in stoichiometric clusters is $>2.8 \AA$, the distances decrease with removal of $\mathrm{O}$ atoms. ${ }^{52}$ For example, in the $\mathrm{Ti}_{4} \mathrm{O}_{7}$ cluster, the Ti-O bonds near the oxygen vacancy compress by $\sim 0.05 \AA$ while the Ti-Ti distance compresses by $0.28 \AA$ and causes the Ti-O-Ti angle to go from $102.5^{\circ}$ in the stoichiometric cluster to $90.4^{\circ}$. We utilized the covalent radius of $\mathrm{Ti}$ atoms $(1.36 \AA)$ to assign the formation of Ti-Ti bonds when their distance is $<2.72 \AA .{ }^{53}$ The suboxide clusters commonly form a $\mathrm{Ti}$-Ti bond on the reduced $\mathrm{Ti}$ atom next to the $\mathrm{O}$ vacancy, demonstrating shared d electrons.

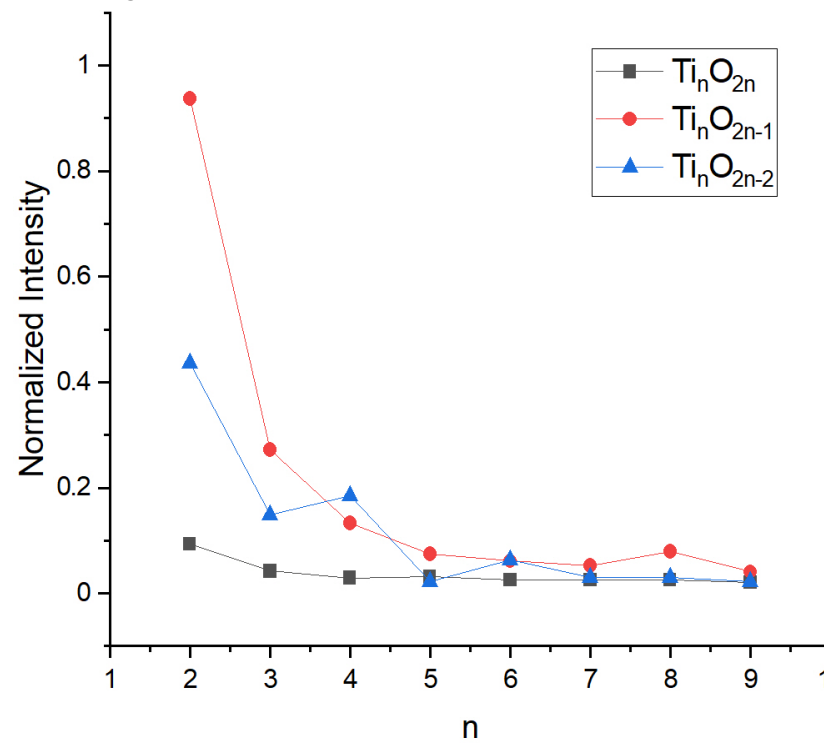

Figure 2. Normalized intensity of the static mass spectra peaks of the $\mathrm{Ti}_{n} \mathrm{O}_{2 n-x}$ clusters generated via laser ablation.

The $\mathrm{E}_{\mathrm{b}}$ increases with $\mathrm{O}$ vacancy and size for each of the cluster series and converges around $7.5 \mathrm{eV}$ (Figure 4). Of particular note, $\mathrm{Ti}_{4} \mathrm{O}_{6}$ has the highest $\mathrm{E}_{\mathrm{b}}$ of all clusters examined, aligning with its prominence in the experimental cluster distribution. Our calculated binding energies vary from previous results ${ }^{47}$ given our variation in cluster geometry. Our calculations suggest that the $\mathrm{Ti}_{\mathrm{n}} \mathrm{O}_{2 \mathrm{n}-2}$ clusters are the most stable, yet experimentally the $\mathrm{Ti}_{\mathrm{n}} \mathrm{O}_{2 \mathrm{n}-1}$ series is comparable in intensity.

Electronic Properties. The density of states (DOS) accessible within the visible spectrum increases with d electrons. In general, with increased number of $O$ vacancies, the $I_{P}$, $\mathrm{HOMO} / \mathrm{LUMO}$ gap, and $\mathrm{O}_{\text {gap }}$ decrease by several $\mathrm{eV}$. The $\mathrm{E}_{\mathrm{a}}$ is smallest for the $\mathrm{Ti}_{n} \mathrm{O}_{2 n-2}$ series and the largest $E_{a}$ varies between
$\mathrm{Ti}_{\mathrm{n}} \mathrm{O}_{2 \mathrm{n}}$ and $\mathrm{Ti}_{\mathrm{n}} \mathrm{O}_{2 \mathrm{n}-1}$ clusters. The $\mathrm{E}_{\mathrm{a}}$ calculated for several clusters are in general agreement with experimental measurements. ${ }^{54}$ Experimental $I_{P}$ values are not available for comparison, but our values align with prior literature calculations, ${ }^{43}$ showing the stoichiometric clusters have large $(>10.0 \mathrm{eV})$ values. $I_{P}$ values have not been previously reported either experimentally or computationally for sub-stoichiometric $\mathrm{Ti}_{\mathrm{n}} \mathrm{O}_{2 \mathrm{n}-\mathrm{x}}$ clusters. Our results show suboxides have lower $E_{x}$ for the $S_{0}$ geometry than $\mathrm{Ti}_{\mathrm{n}} \mathrm{O}_{2 n}$ clusters with the exception of $\mathrm{Ti}_{3} \mathrm{O}_{\mathrm{x}}$ cluster series. The decrease in $\mathrm{E}_{\mathrm{x}}$ suggests a destabilization of electron hole pairs with $\mathrm{O}$ deficiencies. The $\mathrm{E}_{\mathrm{x}}$ is anomalously low in $\mathrm{Ti}_{3} \mathrm{O}_{6}$, and the charge carriers separate to opposite ends of the cluster.

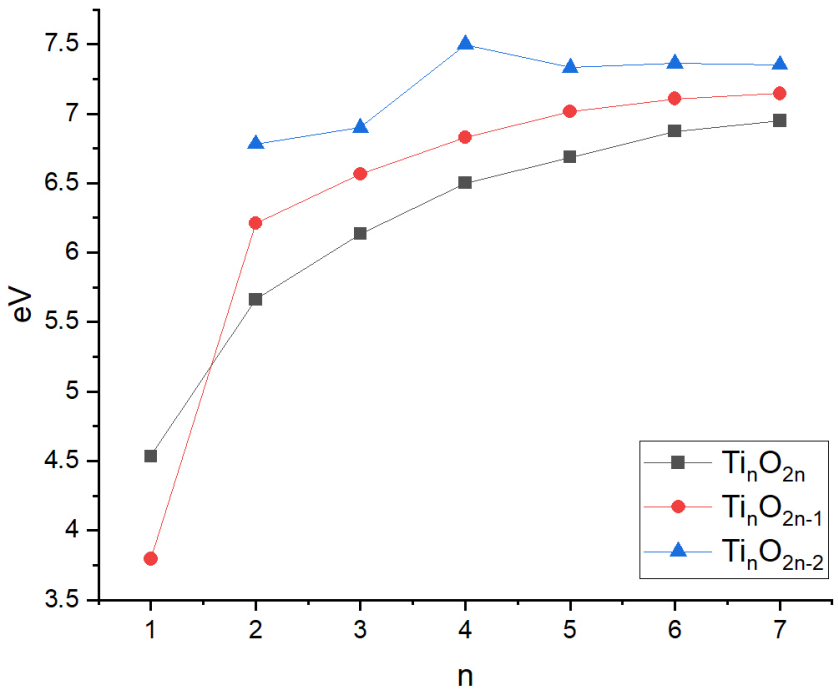

Figure 3. Binding energy per $\mathrm{O}$ atom for $\mathrm{Ti}_{\mathrm{n}} \mathrm{O}_{2 \mathrm{n}-\mathrm{x}}$ clusters.

The HOMO-LUMO gap decreases by multiple eV upon the absence of an $\mathrm{O}$ atom. Disordered bulk $\mathrm{TiO}_{2}$ has shown both conduction band and valence band shifts resulting from $\mathrm{O}$ vacancies. ${ }^{2}$ Increased $\mathrm{O}$ vacancies shift both the occupied and unoccupied orbitals towards the Fermi level (Figure 4). The increase in energies leaves fewer orbitals below the Fermi level and the orbitals become closer in energy in the conduction band. However, the dominant effect of $\mathrm{O}$ vacancies in these clusters is an upshift in the valence states leading to a smaller HOMOLUMO gap compared to stoichiometric clusters. The reduction in bandgap and $\mathrm{O}_{\text {gap }}$ occurs for all suboxide clusters and is consistent with changes in reduced bulk. ${ }^{2}$ These results show that HOMO-LUMO gap can be tuned by changing the size and structures of clusters, providing a way to further tune their electronic and optical characteristics. 


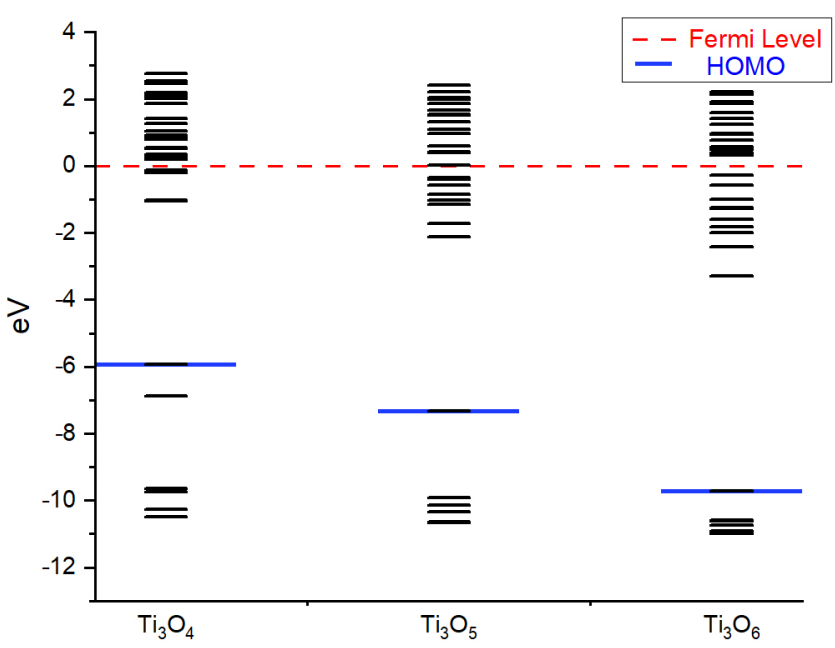

Figure 4. High lying occupied orbitals and low-lying unoccupied orbitals of $\mathrm{Ti}_{3} \mathrm{O}_{4}, \mathrm{Ti}_{3} \mathrm{O}_{5}$, and $\mathrm{Ti}_{3} \mathrm{O}_{6}$ in relation to the Fermi level. The blue line represents the HOMO for each cluster.

A quantum confinement effect is calculated in clusters where the $\mathrm{O}_{\text {gap }}$ of the stoichiometric clusters is near $4.0 \mathrm{eV}$ which is slightly larger than that of bulk anatase $(3.2 \mathrm{eV})$. In contrast, suboxide clusters exhibit a much smaller $\mathrm{O}_{\text {gap }}$ of $<1$ $\mathrm{eV}$ due to the partially filled d orbitals, and therefore contain a continuum of states that are accessible within the visible region. The $\mathrm{O}_{\text {gap }}$ is nearly uniform for a given cluster series (Table 1) and is significantly smaller than the HOMO/LUMO gap as the excited state is a combination of molecular orbitals that incorporates the attraction between the charge carriers. In the bulk phase, $\mathrm{O}$ vacancies act as $\mathrm{F}$-centers creating mid-gap states below the conduction band. At the vacancies, the material is able to absorb visible light, but the electron is trapped at the vacancy site. Similarly, in the clusters, the excess electron density leads to many more states below the traditional bulk bandgap. The $\mathrm{O}$ vacancies act as trapping sites for the low-lying excited states which cannot participate in conduction and charge transport.

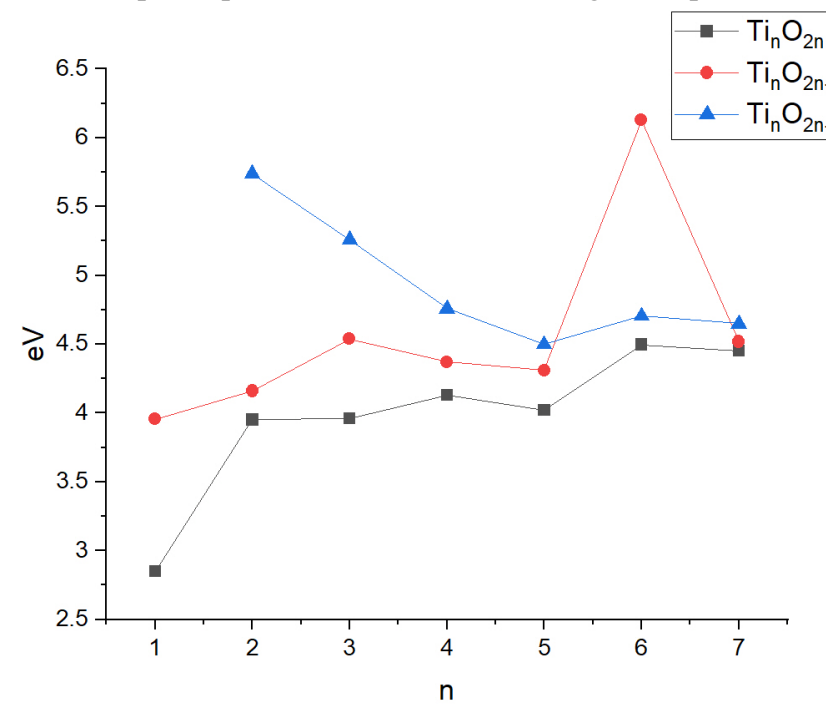

Figure 5. Energy required to access at least 50\% LMCT. For the $\mathrm{Ti}_{\mathrm{n}} \mathrm{O}_{2 n}$ series, the energy of the $\mathrm{S}_{1}$ state is plotted. The energy of cluster $\mathrm{Ti}_{6} \mathrm{O}_{11}$ represents the energy of the $100^{\text {th }}$ excited state as it never had significant LMCT.
Excited State Topology. The subtle balance between onsite electrostatic potential and the electrostatic coupling between electron and hole drives the charge carrier localization and charge transport. Insight into the nature of the excited states that are accessed by visible light absorption and the degree to which different sites allow stabilization of the excited electron and hole components by structural deformation were found through topological parameters of the $\mathrm{S}_{0}$ and $\mathrm{S}_{1}$ states. The presence of the $\mathrm{O}$ vacancy causes the cluster to compress to stabilize the $3 \mathrm{~d}$ electron density. The trends in the $\mathrm{S}_{1}$ cluster geometries uncover a reversal upon photoexcitation, where the cluster stretches to stabilize the hole (Figures S1 and S2). The stoichiometric clusters exhibit an elongation of terminal Ti-O bonds upon photoexcitation which localizes the hole. In contrast, the lack of involvement of the terminal Ti-O bonds of the suboxides leads to a Jahn-Teller (JT) elongation of the bridging Ti-O bonds and related breaking of Ti-Ti bonds. Thus, in suboxides, the Ti-Ti bonds lengthen upon adiabatic relaxation to the $S_{1}$ structure in concert with polaron formation.

Depending on the localization of the excess electron density, the low energy excitations (band gap states) show different behaviors. Subtle changes in the local environment of each cluster affects the charge carrier distributions and related polaronlike formation. The open-shell nature of the suboxide clusters exhibit different properties for the $\mathrm{S}_{1}$ states than the closed shell stoichiometric clusters. Both the $\Lambda$ and $\mathrm{d}_{\mathrm{eh}}$ values calculated for stoichiometric clusters are small (Table S2), revealing a highly ionic character where charges localize on neighboring atoms without overlapping. The $\mathrm{Ti}_{\mathrm{n}} \mathrm{O}_{2 \mathrm{n}}$ clusters are void of $\mathrm{d}$ electrons and the excited states are strictly LMCT in character between the $\mathrm{O}-2 \mathrm{p}$ and Ti-3d orbitals. However, the partially filled d-orbitals of the suboxides profoundly affect the photoexcitation energies and properties by enabling a large density of d-d transitions at low energy. The larger $\Lambda$ values calculated for the suboxides demonstrate that the photoexcitation mechanism transitions from an ionic LMCT character transition for $\mathrm{Ti}_{n} \mathrm{O}_{2 n}$ clusters $(\Lambda<0.3)$ to a covalent MMCT character transition for the sub-stoichiometric series $(\Lambda \sim 0.5)$. In many suboxides, the hole and the electron co-exist on the $\mathrm{Ti}^{3+}$ atom. Although the $\mathrm{O}_{\text {gap }}$ is much smaller in suboxides, the energy required to access a LMCT in the suboxide clusters increases compared to the closed shell clusters (Figure 5). The lack of symmetry of the $\mathrm{Ti}_{6} \mathrm{O}_{11}$ cluster causes it to not show $>50 \%$ LMCT in the first 100 excited states and until $>6 \mathrm{eV}$.

Bulk titania exhibits a sub-nanometer exciton binding radius $^{55,56}$ that is consistent with the small $\mathrm{d}_{\mathrm{eh}}$ we calculated for the clusters. In all clusters, $d_{\text {eh }}$ remains small after adiabatic relaxation (less than half the cluster diameter), indicating a strong $E_{x}$ (Table S2). The $d_{\text {eh }}$ for most suboxide clusters are substantially smaller than their stoichiometric counterparts (Figure 6). In particular, the $\mathrm{d}_{\mathrm{eh}}$ values for many suboxide clusters are $<1.0$ $\AA$, aligning with a high $\mathrm{E}_{\mathrm{x}}$. The relative delocalization of the electron and hole following adiabatic relaxation is larger than the stoichiometric counterparts. 


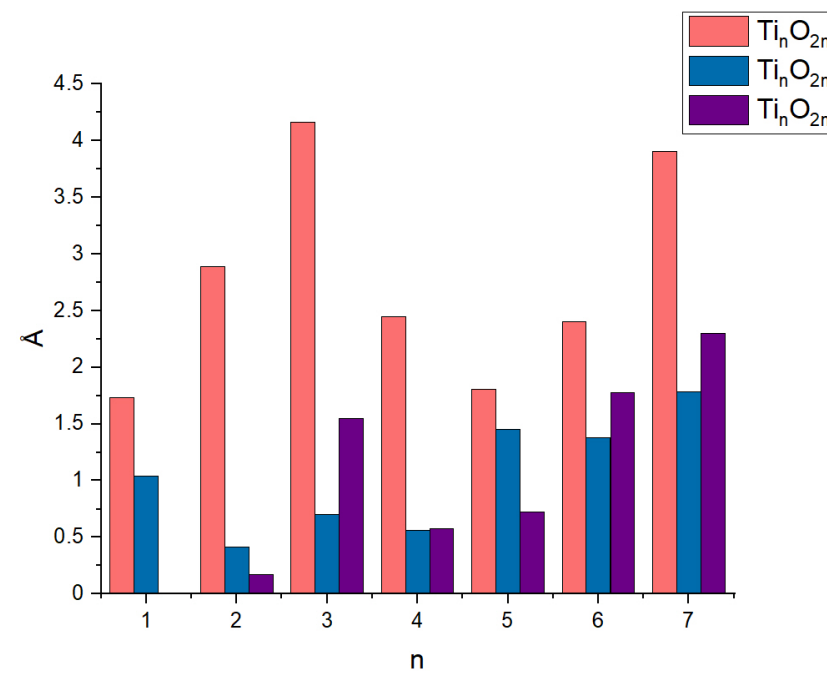

Figure 6. Distance between the hole and electron in the $\mathrm{S}_{1}$ geometries.

In the $\mathrm{Ti}_{\mathrm{n}} \mathrm{O}_{2 \mathrm{n}}$ clusters, the hole is typically contained primarily to the terminal $\mathrm{O}$ atoms, but photoexcitation in the suboxide clusters generally does not involve any $\mathrm{O}$ atoms. In suboxides, the partially filled $3 \mathrm{~d}$ orbitals participate in photoexcitation, leaving behind a hole that adopts their characteristics and is therefore localized on the tri-coordinated $\mathrm{Ti}^{3+}$ sites, which is typically adjacent the $\mathrm{O}$ vacancy site in $\mathrm{Ti}_{\mathrm{n}} \mathrm{O}_{2 \mathrm{n}-1}$, and furthest from the Ti-Ti bond formed within $\mathrm{Ti}_{\mathrm{n}} \mathrm{O}_{2 \mathrm{n}-2}$ clusters. The reduced $\mathrm{Ti}^{3+}$ sites corresponding to $\mathrm{O}$ vacancies are precursors for polaron formation. These suboxide clusters show hole-polaron formation across one or two Ti atoms depending on cluster symmetry. In contrast, the excited d-electron density of suboxides is typically delocalized across many, if not all, of the Ti atoms in the system. Interestingly, this behavior is starkly different than both the stoichiometric clusters ${ }^{29}$ and extended surfaces, ${ }^{57}$ where excess electrons are typically pinned to one $\mathrm{Ti}^{3+}$ site. Thus, tightly bound excitons only appear in the $\mathrm{Ti}_{\mathrm{n}} \mathrm{O}_{2 \mathrm{n}}$ clusters. However, both charge carriers contain a large section of overlapping density in suboxides clusters, reflecting the high $\mathrm{E}_{\mathrm{x}}$.

Our calculations reveal that clusters with stronger hole localization generally exhibit smaller $\mathrm{O}_{\text {gap }}$, which is similar to the shallower gap state found in bulk states upon localization. For example, the $\mathrm{O}_{\text {gap }}$ for $\mathrm{Ti}_{5} \mathrm{O}_{8}$ is $0.2 \mathrm{eV}\left(\sigma_{\mathrm{h}}=2.51 \AA^{3}\right)$, and for $\mathrm{Ti}_{4} \mathrm{O}_{7}$ is $0.58 \mathrm{eV}\left(\sigma_{\mathrm{h}}=3.50 \AA^{3}\right)$. It is clear that the geometric configurations surrounding the $\mathrm{O}$-vacancy generally facilitates hole-polaron formation upon low energy excitations. In contrast, the electron trap sites arise from undercoordinated $\mathrm{Ti}$ atoms that appear in closed shell clusters, such as in $\mathrm{Ti}_{5} \mathrm{O}_{10}$ and $\mathrm{Ti}_{3} \mathrm{O}_{6}$. The electron density shows a preference for tri-coordinated Ti sites but does not localize in any of the suboxides under low energy excitation. Therefore, hole trapping is more common than electron trapping and aligns with the mobilities suggested for bulk titania, where the electrons behave according to the band model and holes migrate through a hopping mechanism.

The charge distributions for the $\mathrm{S}_{0}$ and $\mathrm{S}_{1}$ structures of the $\mathrm{Ti}_{4} \mathrm{O}_{\mathrm{x}}$ and $\mathrm{Ti}_{5} \mathrm{O}_{\mathrm{x}}$ clusters serve as examples to highlight the extreme variation in excited state character that occurs within subnanometer titanium oxide clusters (Figure 7). Similar analysis for the remaining clusters is presented in the SI (Figures S1 and $\mathrm{S} 2$ ). Upon $\mathrm{S}_{1}$ adiabatic relaxation, both $\mathrm{Ti}_{4} \mathrm{O}_{8}$ and $\mathrm{Ti}_{5} \mathrm{O}_{10}$ exhibit exciton formation, whereas the suboxides demonstrate electron density delocalization. $\mathrm{Ti}_{4} \mathrm{O}_{8}$ excitation involves all $\mathrm{O}$ atoms, but only the Ti furthest from the terminal $\mathrm{O}$ groups. The strong $\mathrm{E}_{\mathrm{X}}$ brings the charge carriers together to form a 2-center hole polaron and exciton pair. The partially filled d orbitals of $\mathrm{Ti}_{4} \mathrm{O}_{7}$ cluster exhibits a highly localized hole, centered on the $\mathrm{Ti}^{3+}$ site adjacent the $\mathrm{O}$ vacancy and a delocalized electron, spread over the remaining $\mathrm{Ti}$ atoms. However, there is a preference for both the electron and hole to localize on the tri-coordinated $\mathrm{Ti}$ in $\mathrm{Ti}_{4} \mathrm{O}_{7}$. This strongly localized hole density that overlaps the dominant portion of electron density is also found in many other suboxides and is expected to inhibit the formation of long-lived excited states by facilitating for the photogenerated charge carrier recombination and ultimately reduce catalytic performance. The $\mathrm{T}_{\mathrm{d}}$ symmetry of the $\mathrm{Ti}_{4} \mathrm{O}_{6}$ cluster enables is a unique phenomenon in the suboxide clusters, where both the hole and electron are equally distributed across all Ti atoms, leading to an anomalously large $\sigma_{\mathrm{e}}$ and $\sigma_{\mathrm{h}}$.

Each of the $\mathrm{Ti}_{4} \mathrm{O}_{\mathrm{x}}$ clusters exhibit a different symmetry group and demonstrate unique charge carrier behavior upon photoexcitation. In contrast, the $\mathrm{Ti}_{5} \mathrm{O}_{\mathrm{x}}$ clusters all belong to the same symmetry group and yet reveal a similar range of effects (Figure $7 \mathrm{~b}$ ). The closed shell $\mathrm{Ti}_{5} \mathrm{O}_{10}$ cluster contains a unique tri-coordinated $\mathrm{Ti}$ that serves as an electron localization site. Similar to $\mathrm{Ti}_{4} \mathrm{O}_{8}$, the hole distributes on the neighboring $\mathrm{O}$ atoms in an exciton pair. However, in $\mathrm{Ti}_{5} \mathrm{O}_{9}$, both the hole and the electron are delocalized away from the terminal $\mathrm{O}$. The hole is evenly distributed amongst the two Ti atoms covalently bound together, and very little change in the charge distribution occurs upon adiabatic relaxation. The $\mathrm{Ti}_{5} \mathrm{O}_{8}$ cluster contains a pseudoplanar tri-coordinated $\mathrm{Ti}^{3+}$ site which acts as a trap site for both the electron and the hole upon photoexcitation. The absence of a nearby $\mathrm{Ti}$ atom inhibits $\mathrm{Ti}-\mathrm{Ti}$ bond formation and instead leaves the $\mathrm{Ti}^{3+}$ containing excess electron density. The $\mathrm{Ti}_{5} \mathrm{O}_{8}$ cluster exhibits one of the most delocalized electron densities but, unlike $\mathrm{Ti}_{4} \mathrm{O}_{6}$, it also contains a highly localized hole. This variation and range in topological properties demonstrates that neither symmetry nor oxygen content are the dominant factor in charge localization, but it is instead determined by subtle changes to the local bonding configurations within the clusters. 


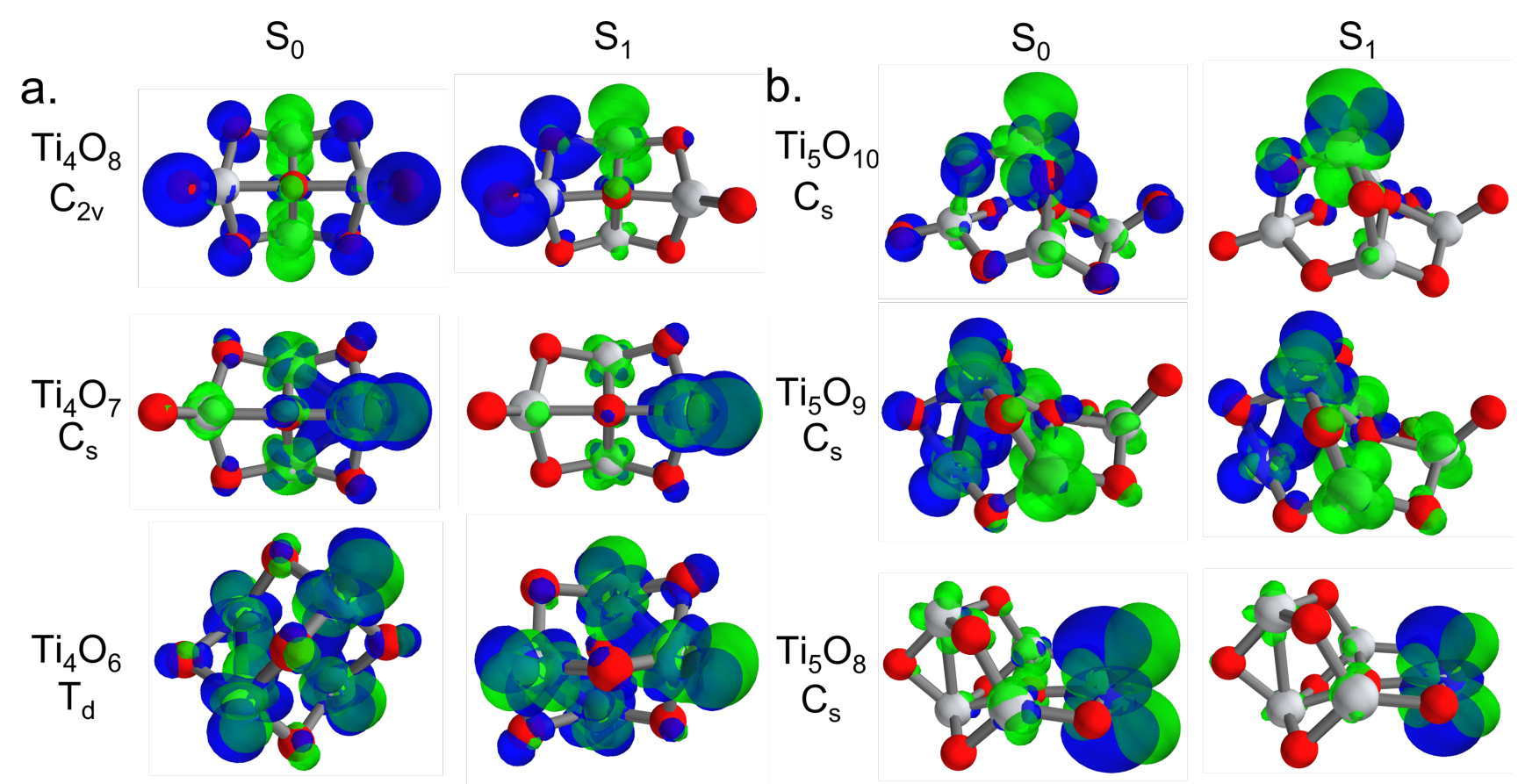

Figure 7. TDA-CAM-B3LYP transition densities for the $\mathrm{S}_{0}$ (left) and $\mathrm{S}_{1}$ (right) states of the a) $\mathrm{Ti}_{4} \mathrm{O}_{8}, \mathrm{Ti}_{4} \mathrm{O}_{7}$, and $\mathrm{Ti}_{4} \mathrm{O}_{6}$ and b) $\mathrm{Ti}_{5} \mathrm{O}_{10}, \mathrm{Ti}_{5} \mathrm{O}_{9}$, and $\mathrm{Ti}_{5} \mathrm{O}_{8}$ clusters at an isodensity of $0.002 / \AA^{3}$. Electron density is green, the hole is blue, Ti atoms are gray, and $\mathrm{O}$ atoms are red.

\section{Conclusions}

A description of excited states of neutral, sub-nanometer $\mathrm{Ti}_{\mathrm{n}} \mathrm{O}_{2 \mathrm{n}}, \mathrm{Ti}_{\mathrm{n}} \mathrm{O}_{2 \mathrm{n}-1}$, and $\mathrm{Ti}_{\mathrm{n}} \mathrm{O}_{2 \mathrm{n}-2}$ clusters is presented using TDDFT calculations. The $\mathrm{O}$ deficient clusters commonly contain covalent $\mathrm{Ti}$-Ti bonds to stabilize the $3 \mathrm{~d}$ electron density that is not found in the stoichiometric clusters. Both $\mathrm{Ti}_{2} \mathrm{O}_{2}$ and $\mathrm{Ti}_{4} \mathrm{O}_{6}$ form higher symmetry geometries which distributes the charge carriers making for stable geometries that accounts for their relatively intense signals in experimental cluster distributions. Our calculations reveal that the introduction of $\mathrm{O}$ vacancies in subnanometer titania improves visible-light absorption and is accompanied by partially filled d-orbitals that influence the excited state properties of the clusters. In suboxide clusters, the low-lying excited states are metal-to-metal charge transfer in contrast to the stoichiometric clusters which exhibit ligand-tometal charge transfer. The localization of d-electrons on Ti sites generally produces a compression of nearby bonds, whereas the localization of the hole density leads to local bond elongation. Although the d-electrons tend to localize in the vicinity of the $\mathrm{O}$ defect, they often occupy multiple Ti sites. The electron does not localize on a single Ti site unless bound to a hole in an exciton pair. The reduced $\mathrm{Ti}^{3+}$ atom(s) act as exciton trapping sites in these sub-nanometer materials, analogous to the electron trapping in undercoordinated $\mathrm{Ti}^{3+}$ cation centers that accompany $\mathrm{O}$ defect sites in bulk and surface sites. Our results demonstrate that these suboxide clusters capture the important features of oxygen vacancy sites in bulk $\mathrm{TiO}_{2}$. Further, the variation in local bonding environment and relative charge density distributions of these sub-nanometer clusters highlight structural patterns that can be applied for designing new materials containing long-lived excited states and low absorption energy.

\section{SUPPORTING INFORMATION}

Energetic and topological properties calculated at both the ground and excited state, including coordinates for the optimized $\mathrm{S}_{0}$ and $\mathrm{S}_{1}$ cluster geometries. Table $\mathrm{S} 1$ shows the ionization potentials, electron affinities, optical gaps. Table S2 reports the topological descriptors $(\Lambda, d, \sigma)$. Figure S1 and S2 show the structures for the $\mathrm{Ti}_{\mathrm{n}} \mathrm{O}_{2 \mathrm{n}-1}$, and $\mathrm{Ti}_{\mathrm{n}} \mathrm{O}_{2 \mathrm{n}-2}$ clusters respectively. The material is free of charge via the Internet at http://pubs.acs.org.

\section{CORRESPONDING AUTHOR}

*Scott.Sayres@asu.edu

\section{ORCID}

Lauren F. Heald: 0000-0001-5433-9753

Jacob M. Garcia: 0000-0002-4491-4408

Scott G. Sayres: 0000-0002-0439-4196

\section{Notes}

The authors declare no competing financial interests

\section{AUTHOR CONTRIBUTIONS}

L.F.H. and S.G.S and performed the calculations. J.M.G obtained the experimental cluster distribution, and L.F.H and S.G.S wrote the paper with contributions from all authors.

\section{Acknowledgements}

J.M.G also acknowledges support from Western Alliance to Expand Student Opportunities (WAESO) Louis Stokes Alliance for Minority Participation (LSAMP) Bridge to Doctorate (BD) National Science Foundation (NSF) Grant No. HRD-1702083.

Chen, X.; Mao, S. S. Titanium Dioxide Nanomaterials: Synthesis, Properties, Modifications and Applications. Chem. Rev. 2007, 107 (7), 2891-2959. 
Review of Its Properties and Conflicting Trends. Chem. Eng. J. 2020, 389, 123918.

(3) Hagfeldt, A.; Grätzel, M. Molecular Photovoltaics. Acc. Chem. Res. 2000, 33 (5), 269-277.

(4) Thompson, T. L.; Yates, J. T. Surface Science Studies of the Photoactivation of $\mathrm{TiO}_{2}$ New Photochemical Processes. Chem. Rev. 2006, 106 (10), 4428-4453.

(5) Zhao, W.-N.; Liu, Z.-P. Mechanism and Active Site of Photocatalytic Water Splitting on Titania in Aqueous Surroundings. Chem. Sci. 2014, 5, 2256-2264.

(6) Guo, Y.; Li, J.-F.; Niu, X.; Markovits, A.; Zhang, R.-Q Composition Dependent Reactivity of Titanium Oxide Clusters. Phys. Chem. Chem. Phys. 2016, 18 (15), 10594-10599.

(7) Richter, C.; Schmuttenmaer, C. A. Exciton-like Trap States Limi Electron Mobility in $\mathrm{TiO}_{2}$ Nanotubes. Nat. Nanotechnol. 2010, 5 (11), 769-772.

(8) Gallart, M.; Cottineau, T.; Hönerlage, B.; Keller, V.; Keller, N.; Gilliot, P. Temperature Dependent Photoluminescence of Anatase and Rutile $\mathrm{TiO}_{2}$ Single Crystals: Polaron and SelfTrapped Exciton Formation. J. Appl. Phys. 2018, 124 (13).

(9) Carey, J. J.; McKenna, K. P. Does Polaronic Self-Trapping Occur at Anatase $\mathrm{TiO}_{2}$ Surfaces? J. Phys. Chem. C 2018, 122 (48), 27540-27553.

(10) Rahimi, N.; Pax, R. A.; Gray, E. M. A. Review of Functional Titanium Oxides. I: $\mathrm{TiO}_{2}$ and Its Modifications. Prog. Solid State Chem. 2016, 44 (3), 86-105.

(11) Niu, M.; Tan, H.; Cheng, D.; Sun, Z.; Cao, D. Bandgap Engineering of Magnéli Phase $\mathrm{Ti}_{\mathrm{n}} \mathrm{O}_{2 \mathrm{n}-1}$ : Electron-Hole SelfCompensation. J. Chem. Phys. 2015, 143 (5).

(12) Sheng, X.; Chen, L.; Xu, T.; Zhu, K.; Feng, X. Understanding and Removing Surface States Limiting Charge Transport in $\mathrm{TiO}_{2}$ Nanowire Arrays for Enhanced Optoelectronic Device Performance. Chem. Sci. 2016, 7 (3), 1910-1913.

(13) Smith, J. R.; Walsh, F. C.; Clarke, R. L. Electrodes Based on Magnéli Phase Titanium Oxides: The Properties and Applications of Ebonex ${ }^{\circledR}$ Materials. J. Appl. Electrochem. 1998, 28 (10), 1021-1033.

(14) Walsh, F. C.; Wills, R. G. A. The Continuing Development of Magnéli Phase Titanium Sub-Oxides and Ebonex ${ }^{\circledR}$ Electrodes. Electrochim. Acta 2010, 55 (22), 6342-6351.

(15) Yan, J.; Wu, G.; Guan, N.; Li, L.; Li, Z.; Cao, X. Understanding the Effect of Surface/Bulk Defects on the Photocatalytic Activity of $\mathrm{TiO}_{2}$ : Anatase versus Rutile. Phys. Chem. Chem. Phys. 2013, 15 (26), 10978-10988.

(16) Arif, A. F.; Balgis, R.; Ogi, T.; Iskandar, F.; Kinoshita, A.; Nakamura, K.; Okuyama, K. Highly Conductive Nano-Sized Magnéli Phases Titanium Oxide (TiOx). Sci. Rep. 2017, 7, 1-9.

(17) Chen, X.; Liu, L.; Yu, P. Y.; Mao, S. S. Increasing Solar Absorption for Photocatalysis with Black Hydrogenated Titanium Dioxide Nanocrystals. Science. 2011, 331 (6018), 746750 .

(18) Elbanna, O.; Fujitsuka, M.; Kim, S.; Majima, T. Charge Carrier Dynamics in $\mathrm{TiO}_{2}$ Mesocrystals with Oxygen Vacancies for Photocatalytic Hydrogen Generation under Solar Light Irradiation. J. Phys. Chem. C 2018, 122 (27), 15163-15170.

(19) Han, W. Q.; Zhang, Y. Magńli Phases $\mathrm{Ti}_{\mathrm{n}} \mathrm{O}_{2 \mathrm{n}-1}$ Nanowires: Formation, Optical, and Transport Properties. Appl. Phys. Lett. 2008, 92 (20), 1-4.

(20) Ho, Y. C.; Hoque, M. N. F.; Stoneham, E.; Warzywoda, J.; Dallas, T.; Fan, Z. Reduction of Oxygen Vacancy Related Traps in $\mathrm{TiO}_{2}$ and the Impacts on Hybrid Perovskite Solar Cells. J. Phys. Chem. C 2017, 121 (43), 23939-23946.

(21) Li, T.; Hong, F.; Yang, K.; Yue, B.; Tamura, N.; Wu, H.; Cheng, Z.; Wang, C. Metastable Oxygen Vacancy Ordering State and Improved Memristive Behavior in TiO2 Crystals. Sci. Bull. 2020, $65(8), 631-639$.

(22) Naldoni, A.; Allieta, M.; Santangelo, S.; Marelli, M.; Fabbri, F.; Cappelli, S.; Bianchi, C. L.; Psaro, R.; Dal Santo, V. Effect of Nature and Location of Defects on Bandgap Narrowing in Black $\mathrm{TiO}_{2}$ Nanoparticles. J. Am. Chem. Soc. 2012, 134 (18), 76007603.

(23) Nam, Y.; Li, L.; Lee, J. Y.; Prezhdo, O. V. Strong Influence of Oxygen Vacancy Location on Charge Carrier Losses in Reduced
TiO2 Nanoparticles. J. Phys. Chem. Lett. 2019, 10 (11), 26762683.

Su, J.; Zou, X.; Chen, J.-S. Self-Modification of Titanium Dioxide Materials by $\mathrm{Ti}^{3+}$ and/or Oxygen Vacancies: New Insights into Defect Chemistry of Metal Oxides. RSC Adv. 2014, 4 (27), 13979-13988.

(25) Deák, P.; Aradi, B.; Frauenheim, T. Quantitative Theory of the Oxygen Vacancy and Carrier Self-Trapping in Bulk $\mathrm{TiO}_{2}$. Phys. Rev. B - Condens. Matter Mater. Phys. 2012, 86 (19), 1-8.

(26) Harada, S.; Tanaka, K.; Inui, H. Thermoelectric Properties and Crystallographic Shear Structures in Titanium Oxides of the Magnèli Phases. J. Appl. Phys. 2010, 108 (8), 083703.

(27) Roh, B.; Macdonald, D. D. Effect of Oxygen Vacancies in Anodic Titanium Oxide Films on the Kinetics of the Oxygen Electrode Reaction. Russ. J. Electrochem. 2007, 43 (2), 125-135. https://doi.org/10.1134/S1023193507020012.

(28) Kim, S.; Ko, K. C.; Lee, J. Y.; Illas, F. Single Oxygen Vacancies of $\left(\mathrm{TiO}_{2}\right)_{35}$ as a Prototype Reduced Nanoparticle: Implication for Photocatalytic Activity. Phys. Chem. Chem. Phys. 2016, 18 (34), 23755-23762.

(29) Garcia, J. M.; Heald, L. F.; Shaffer, R. E.; Sayres, S. G Oscillation in Excited State Lifetimes with Size of SubNanometer Neutral $\left(\mathrm{TiO}_{2}\right)_{\mathrm{n}}$ Clusters Observed with Ultrafast Pump-Probe Spectroscopy. J. Phys. Chem. Lett. 2021, 12 (16), 4098-4103.

(30) Frisch, M. J.; Trucks, G. W.; Schlegel, H. B.; Scuseria, G. E.; Robb, M. A.; Cheeseman, J. R.; Scalmani, G.; Barone, V.; Mennucci, B.; Petersson, G. A.; Nakatsuji, H.; Caricato, M.; Li, X.; Hratchian, H. P.; Izmaylov, A. F.; Bloino, J.; Zheng, G.; Sonnenberg, J. L.; Hada, M.; Ehara, M.; Toyota, K.; Fukuda, R.; Hasegawa, J.; Ishida, M.; Nakajima, T.; Honda, Y.; Kitao, O.; Nakai, H.; Vreven, T.; Montgomery Jr., J. A.; Peralta, J. E.; Ogliaro, F.; Bearpark, M.; Heyd, J. J.; Brothers, E.; Kudin, K. N.; Staroverov, V. N.; Kobayashi, R.; Normand, J.; Raghavachari, K.; Rendell, A.; Burant, J. C.; Iyengar, S. S.; Tomasi, J.; Cossi, M.; Rega, N.; Millam, J. M.; Klene, M.; Knox, J. E.; Cross, J. B.; Bakken, V.; Adamo, C.; Jaramillo, J.; Gomperts, R.; Stratmann, R. E.; Yazyev, O.; Austin, A. J.; Cammi, R.; Pomelli, C.; Ochterski, J. W.; Martin, R. L.; Morokuma, K.; Zakrzewski, V. G.; Voth, G. A.; Salvador, P.; Dannenberg, J. J.; Dapprich, S.; Daniels, A. D.; Farkas, O.; Foresman, J. B.; Ortiz, J. V; Cioslowski, J.; Fox, D. J. Gaussian16 (Revision A.03), Gaussian Inc. Wallingford CT. Gaussian16 (Revision A.03). 2016.

(31) Yanai, T.; Tew, D. P.; Handy, N. C. A New Hybrid ExchangeCorrelation Functional Using the Coulomb-Attenuating Method (CAM-B3LYP). Chem. Phys. Lett. 2004, 393 (1-3), 51-57. https://doi.org/10.1016/j.cplett.2004.06.011.

(32) Hirata, S.; Head-Gordon, M. Time-Dependent Density Functional Theory within the Tamm-Dancoff Approximation. Chem. Phys. Lett. 1999, 314 (3-4), 291-299.

(33) Harb, M.; Rabilloud, F.; Simon, D.; Rydlo, A.; Lecoultre, S.; Conus, F.; Rodrigues, V.; Félix, C. Optical Absorption of Small Silver Clusters: $\mathrm{Ag}_{\mathrm{n}},(\mathrm{N}=4-22)$. J. Chem. Phys. 2008, 129 (19).

(34) Berardo, E.; Hu, H. S.; Shevlin, S. A.; Woodley, S. M.; Kowalski, K.; Zwijnenburg, M. A. Modeling Excited States in $\mathrm{TiO}_{2}$ Nanoparticles: On the Accuracy of a TD-DFT Based Description. J. Chem. Theory Comput. 2014, 10 (3), 1189-1199. https://doi.org/10.1021/ct4010273.

(35) Berardo, E.; Kaplan, F.; Bhaskaran-Nair, K.; Shelton, W. A.; Van Setten, M. J.; Kowalski, K.; Zwijnenburg, M. A. Benchmarking the Fundamental Electronic Properties of Small $\mathrm{TiO} 2$ Nanoclusters by GW and Coupled Cluster Theory Calculations. J. Chem. Theory Comput. 2017, 13 (8), 3814-3828. https://doi.org/10.1021/acs.jctc.7b00538.

(36) Garcia, J. M.; Heald, L. F.; Shaffer, R. E.; Sayres, S. G. Oscillation in Excited State Lifetimes with Size of SubNanometer Neutral (TiO2)NClusters Observed with Ultrafast Pump-Probe Spectroscopy. J. Phys. Chem. Lett. 2021, 12 (16), 4098-4103. https://doi.org/10.1021/acs.jpclett.1c00840.

(37) Mewes, S. A.; Plasser, F.; Krylov, A.; Dreuw, A. Benchmarking Excited-State Calculations Using Exciton Properties. J. Chem. Theory Comput. 2018, 14 (2), 710-725. https://doi.org/10.1021/acs.jctc.7b01145. 
(38) Bäppler, S. A.; Plasser, F.; Wormit, M.; Dreuw, A. Exciton Analysis of Many-Body Wave Functions: Bridging the Gap between the Quasiparticle and Molecular Orbital Pictures. Phys. Rev. A - At. Mol. Opt. Phys. 2014, 90 (5), 45-48. https://doi.org/10.1103/PhysRevA.90.052521.

Peach, M. J. G.; Benfield, P.; Helgaker, T.; Tozer, D. J. Excitation Energies in Density Functional Theory: An Evaluation and a Diagnostic Test. J. Chem. Phys. 2008, 128 (4), 044118. https://doi.org/10.1063/1.2831900.

(40) Ganguly Neogi, S.; Chaudhury, P. Structural, Spectroscopic Aspects, and Electronic Properties of $\left(\mathrm{TiO}_{2}\right)_{\mathrm{n}}$ Clusters: A Study Based on the Use of Natural Algorithms in Association with Quantum Chemical Methods. J. Comput. Chem. 2014, 35 (1), 5161.

(41) Berardo, E.; Hu, H.-S.; Shevlin, S. A.; Woodley, S. M.; Kowalski, K.; Zwijnenburg, M. A. Modeling Excited States in $\mathrm{TiO}_{2}$ Nanoparticles: On the Accuracy of a TD-DFT Based Description. J. Chem. Theory Comput. 2014, 10 (3), 1189-1199.

(42) Berardo, E.; Hu, H. S.; Van Dam, H. J. J.; Shevlin, S. A.; Woodley, S. M.; Kowalski, K.; Zwijnenburg, M. A. Describing Excited State Relaxation and Localization in $\mathrm{TiO}_{2}$ Nanoparticles Using TD-DFT. J. Chem. Theory Comput. 2014, 10 (12), 55385548.

(43) Berardo, E.; Kaplan, F.; Bhaskaran-Nair, K.; Shelton, W. A.; Van Setten, M. J.; Kowalski, K.; Zwijnenburg, M. A. Benchmarking the Fundamental Electronic Properties of $\mathrm{Small}_{\mathrm{TiO}}$ Nanoclusters by GW and Coupled Cluster Theory Calculations. J. Chem. Theory Comput. 2017, 13 (8), 3814-3828.

(44) Li, S.; Dixon, D. A. Molecular Structures and Energetics of the $\left(\mathrm{TiO}_{2}\right)_{\mathrm{n}}(\mathrm{n}=1-4)$ Clusters and Their Anions. J. Phys. Chem. A 2008, 112 (29), 6646-6666.

(45) Qu, Z.-W.; Kroes, G.-J. Theoretical Study of the Electronic Structure and Stability of Titanium Dioxide Clusters $\left(\mathrm{TiO}_{2}\right)_{\mathrm{n}}$ with $\mathrm{n}=1-9$. . J. Phys. Chem. B 2006, 110, 8998-9007.

(46) Rana, T. H.; Kumar, P.; Solanki, A. K.; Skomski, R.; Kashyap, A. Ab-Initio Study of Free Standing $\mathrm{TiO}_{2}$ Clusters: Stability and Magnetism. J. Appl. Phys. 2013, 113 (17).

(47) Du, H.; Jia, Y.; Niu, C.; Hu, K.; Li, H.; Yu, L. The Ratio Law of the Structure Evolution and Stability for $\mathrm{Ti}_{\mathrm{n}} \mathrm{O}_{\mathrm{m}}(\mathrm{n}=3-18, \mathrm{~m}=1-$ 2n) Clusters. Chem. Phys. Lett. 2019, 731, 136574.

(48) W. C. Wiley and I. H. McLaren. Time-of-Flight Mass Spectrometer with Improved Resolution. Rev. Sci. Instrum. 1955, 26 (12), 1150-1157.

(49) Garcia, J. M.; Shaffer, R. E.; Sayres, S. G. Ultrafast Pump-Probe Spectroscopy of Finite-Sized Neutral Iron Oxide Clusters. Phys. Chem. Chem. Phys. 2020, 22, 24624-24632.

(50) Foltin, M.; Stueber, G. J.; Bernstein, E. R. On the Growth Dynamics of Neutral Vanadium Oxide and Titanium Oxide Clusters. J. Chem. Phys. 1999, 111 (21), 9577-9586.

(51) Dargouthi, S.; Boughdiri, S.; Tangour, B. Stabilizing of the Transitory Species $\left(\mathrm{TiO}_{2}\right)_{2}$ by Encapsulation into Carbon Nanotubes. Acta Chim. Slov. 2015, 62 (2), 445-451.

(52) Hao, Y. N.; Chen, T.; Zhang, X.; Zhou, H.; Ma, Y. Ti-Ti $\sigma$ Bond at Oxygen Vacancy Inducing the Deep Defect Level in Anatase $\mathrm{TiO}_{2}$ (101) Surface. J. Chem. Phys. 2019, 150 (22), 1-9.

(53) Pyykkö, P.; Atsumi, M. Molecular Single-Bond Covalent Radii for Elements 1-118. Chem. - A Eur. J. 2009, 15 (1), 186-197.

(54) Wu, H.; Wang, L. S. Electronic Structure of Titanium Oxide Clusters: $\mathrm{TiO}_{\mathrm{y}}(\mathrm{Y}=1-3)$ and $\left(\mathrm{TiO}_{2}\right)_{\mathrm{n}}(\mathrm{N}=1-4)$. J. Chem. Phys. 1997, $107(20), 8221-8228$.

(55) Serpone, N.; Lawless, D.; Khairutdinov, R. Size Effects on the Photophysical Properties of Colloidal Anatase $\mathrm{TiO}_{2}$ Particles: Size Quantization or Direct Transitions in This Indirect Semiconductor? J. Phys. Chem. 1995, 99 (45), 16646-16654.

(56) Monticone, S.; Tufeu, R.; Kanaev, A. .; Scolan, E.; Sanchez, C. Quantum Size Effect in $\mathrm{TiO}_{2}$ Nanoparticles: Does It Exist? Appl. Surf. Sci. 2000, 162-163 (3), 565-570.

(57) Setvin, M.; Franchini, C.; Hao, X.; Schmid, M.; Janotti, A.; Kaltak, M.; Van De Walle, C. G.; Kresse, G.; Diebold, U. Direct View at Excess Electrons in $\mathrm{TiO}_{2}$ Rutile and Anatase. Phys. Rev. Lett. 2014, 113 (8). 
Insert Table of Contents artwork here

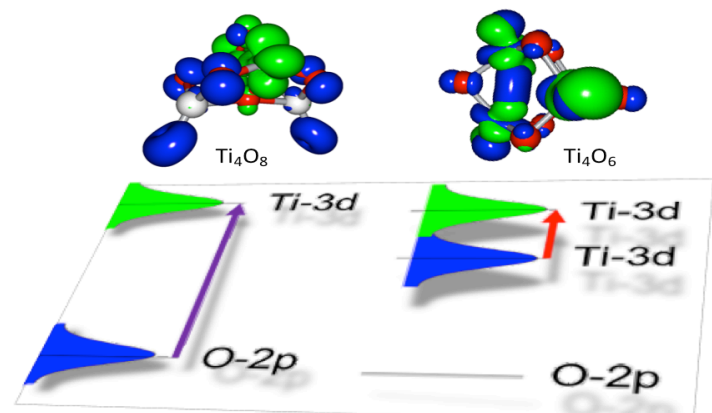

10 